Morten Knudsen

\title{
Autolysis Within Organizations: A Case Study
}

»The system will eat itself. «

(from Truffaut's Fahrenheit 451)

Zusammenfassung: Der Beitrag zeigt, wie die von Niklas Luhmann entwickelte Systemtheorie für eine empirische Analyse von Lärm und lärmerzeugenden Mechanismen geöffnet werden kann. Die dem Artikel zugrunde liegende analytische Strategie ist die Beobachtung der Operationen, die ein soziales System konstituieren. Eine entsprechende Analyse macht auf das Fehlen von Anschlusskommunikation und auf die aktive Produktion von Lärm (verstanden als Operationen ohne Anschlüsse) aufmerksam, d.h. sie öffnet die Analyse für systemische Autolysis (Selbstauflösung). Darauf aufbauend wird eine operationale Analyse organisationaler Kommunikation durchgeführt, die die Leitdifferenz Ereignis/Rekursivität benutzt. Der Artikel ist in sechs Abschnitte gegliedert. Nach der Einleitung wird eine operational-analytische Strategie skizziert (I). Danach wird das Konzept der Autolysis vorgestellt (II). Eine Fallstudie über das Entscheidungsverhalten in einer Organisation des Gesundheitswesens liefert dann Beispiele für organisationalen Lärm im Sinne von Entscheidungen ohne Anschlusskommunikationen (III). Die Fallstudie demonstriert eine aktive Produktion von Geräuschen und identifiziert vier Mechanismen, die ein Rauschen erzeugen (IV). Danach wird diskutiert, wie die Organisation den Lärm beobachtet, den sie erzeugt (V). Abschließend werden die Resultate einer Zusammenführung der operational-analytischen Zugangsweise und des Konzepts der Autolysis identifiziert und weiterführende Perspektiven skizziert.

\section{Introduction}

The notion of improbability is a cornerstone in Luhmann's work. It establishes a distance to the familiar, making it require explanation as it disrupts the direct identity between reality and knowledge (Luhmann 1997, 37). Analyses are generated by asking how something (order, communication, systems) is made more probable (Luhmann 1981a; 1995, 114ff; 1997, 190f; 2000, 46; Willke 1987). Each successful communication is seen as a solution to the problem of the improbability of communication and the concepts of systems theory (structure, symbolically generalized media, deparadoxization, reduction of complexity, Eigen-values, Kontingenzformeln etc.) are required to explain how such communication is made more likely. It is the production of order out of noise that is to be explained. Order is improbable and needs explanation, whereas 
disorder is taken for granted. This theoretical strategy is reflected in the concept of autopoiesis and in the functional method.

This article reverses the starting point. Instead of taking disorder, or noise, as input for the analyses it takes order for granted and observes noise as an output, as something that has been actively produced. Theoretically, it introduces the concept of autolysis (self-dissolution) as a counter-concept to autopoiesis. Methodologically, the article stems from an interest in developing empirical analyses of communication at an operational level. Together these two points of departure lead to a case-analysis of how an organizational system actively dissolves some of its own operations. The article does not question the validity of the concept of autopoiesis or of the premise of the improbability of communication. Instead, it takes another starting point and raises the question: What will we observe if autolysis is taken as the theoretical focus and if we make our observations of communicative operations against the distinction event/recursivity?

The argument proceeds in the following steps: First, I present an outline of what might be called an operation-analytical strategy. It is a strategy aimed at observing the operations that constitute communication. Then I introduce the concept of autolysis as a counter-concept to autopoiesis and indicate processes in which operations do not establish connections and thereby dissolve. These two suggestions guide the subsequent case-analysis of a health care organization, in which many decisions do not establish any connection. In the final section I discuss what the combination of an operation-analytical strategy and the concept of autolysis might lead to when used as input for further analyses.

\section{An operation-analytical strategy}

Both the concept of autopoiesis and the functional method (Luhmann 1995; 1997; 2004) direct the analytic gaze toward the emergence and stabilization of communication and thus toward the order of social systems. Where hermeneutics observes against a question/answer distinction (to understand a text means to understand which question it is an answer to), a functional approach observes against a problem/solution distinction (to understand something means to understand which problem it solves). The analysis consists of combining the solution with a problem and thus also defining the sense in which the studied phenomenon is a solution. The functional method has the solution-character of the studied phenomenon as a pre-analytical premise.

While the functional method continues to play a central role in systems theory, its role has none the less become less distinct as Luhmann, inspired by G. Spencer Brown, developed his idea of observation. The problem/solution distinction is supplemented with a series of other distinctions, guiding and generating analytical observations of communication. Some of the prominent 
distinctions are system/environment (analyses of differentiation), unity/difference (analyses of forms), meaning/condensation (historical analyses of semantics), form/media (analyses of media) (Andersen 2003). At present it is not clear whether the functional method still has pride of place in systems theory - or whether the idea of one central distinction (with many sub-distinctions) has been replaced by a variety of different analytical strategies using diverse guiding distinctions. This paper, in any case, wishes to contribute to the trend toward experimentation. My suggestion is to supplement the analytical strategies mentioned with a strategy directed at the multiplicity of operations ${ }^{1}$ that constitute social systems - while using the distinction event/recursivity as a Leitdifferenz - a guiding distinction. In order to clarify this suggestion I shall briefly present the concept of operation.

\section{Observation of operations}

Luhmann characterizes the basic unities of a social system as operations (Luhmann 1990, 37; 2000, 45). Social systems are solely constituted by operations (Clam 2000, 73f.) and the operations are reproduced and identified through recursive networks of operations (Luhmann 1990, 37). An operation is at the same time an event and a connection. Operations are events as they are actualisations of possibilities which disappear at the moment of their emergence. They have no durability (apart from the time it takes to observe them) (Luhmann 1993b, 50; 1997, 71f.). This radical temporal perspective (the operations of the system disappearing just after their emergence) raises the question of how one gets from one event to the next (Luhmann 1995b, 36). How are connections between events established?

The answer is that the recursive linkage is made in every operation (Luhmann $1993 b, 45)$ as the operation refers to other events and is itself being referred to - and through this reference is realized as an operation (and not only an event). Every single event only wins its meaning as it refers to others and limits what they may mean - and determines itself through this (Luhmann 1997, 73). The operations are produced and determined as they refer to past and future operations (Luhmann 1993b, 44f.). As Luhmann puts it: »Das System kann eigene Operationen nur im Anschluss an eigene Operationen und im Vorgriff auf weitere Operationen desselben Systems konstituieren. (Luhmann 1997, 67). The events are identified through the systems (i.e. a network of recursively connected operations) which they themselves constitute $(1990,37)$. The unity of

1 The operational level of communication seems to be rather neglected by analyses based on a functional method - at least judging from the analyses actually made. This may be because the functional method directs attention to mechanisms that enable the communicative operations and not towards the operations as actual events. One of the few to work systems theoretically with communication at the operational level is W. L. Schneider. He analyzes the connection in smaller parts of interactive communication (Schneider 2004). 
the system emerges operationally; it is constituted by the connections between operations (Clam 2000; Fuchs/Luhmann 1997).

The term applied to the reference of events to past or future events is recursivity. And a recursive network is a network in which the operations refer to other operations in the same network. Thus the operation is both an event and the reference to other events within this event. The communicative events must connect to earlier events and must themselves have connectivity (Anschlussfähigkeit) for future events in order to be realized as operations (Luhmann 2000, 48).

This raises the question of how recursivity is realized. How does systems theory indicate the relation between events, i.e., the unity of the difference in time between the disappearing event A and the emerging event B (Luhmann 2000, 56)? We may begin to answer this question by means of the concept of understanding. In systems theory, understanding does not take place in the psychic system but in communication, as utterances imply a certain understanding of the previous utterances (Schneider 1994, 164f.). According to Luhmann, to understand is to distinguish between utterance and information and to use this as a basis for connections with further behaviour (Luhmann 1995, 141). Understanding is shown in subsequent behaviour (Luhmann 1995, 143-144). Thus it is the reaction (imbedded in future utterances) to the utterance that completes the communication. If the utterance is not traceable in a subsequent utterance, then there has been no communication. Understanding means that an utterance makes a difference for a subsequent utterance and it is in the influence of this subsequent utterance that the operation is fulfilled. Understanding brings an operation to an end, to a unity of communication. But this end has the form of a transition to further communication (Luhmann 1997, 83) since understanding is realized in an utterance which may again be understood in the course of further communication. Understanding, and thus the fulfilment of the operation, lies in the discipline of connections between events (Stäheli 2000, 119f.).

Recursivity is realized when operations use previous operations as information and also anticipate themselves as information for further operations. To observe operations against the distinction event/recursivity is to observe whether events connect to each other, i.e., whether a communicative event makes a difference to another event. The distinction makes it possible to distinguish between operations with and without (in which case they are not operations but remain events) recursive connections.

In the case presented below, we examine the operations of an organization. I shall therefore briefly relate the above discussion of recursivity to an organizational system. 


\section{Decisions}

According to Luhmann the operations of organizations have the form of decisions and organizations consist of recursively connected decisions (Luhmann 2000). I will therefore show how the idea of recursivity outlined above is specified in relation to decisions.

The necessity of recursivity becomes obvious if you observe decisions. If no one connects to a decision it turns out not to have been a decision, but just talk. Decisions are, as Dirk Baecker says, virtual $(1999,132)$. Only the connections resulting from following decisions turn a decision into what it was pretending to be all the time: a decision. Thus the decision is the unity of the utterance of the decision and the connection to it (which happens when a further decision connects to it). One decision uses another as information that limits its room to manoeuvre. Decisions establish premises for further decisions like a chain of decisions connecting to each other. The utterance of the decision and the connection to it are not simultaneous. A decision's connection is realized in the utterance of a new decision. A decision pretends to be a decision even though at the time it is only following decisions which, if they connect, constitute the decision as a »real « decision. This, of course, ends in a logical problem: as the operations are constituted backwards, the last element is never finished. It reaches all the way back in the chain because the last element, being unfinished, cannot constitute the penultimate etc. (Fuchs 2003). This logical impossibility of complete and absolutely certain closure does not, however, make it impossible to get a sense of what the process might have been like. Instead it reminds us that we must be ready to re-interpret our observations. We may have to change our observations of past operations in the light of later operations.

The suggestion presented here, then, is to use the distinction event/recursivity in the observation of communication. Whereas the problem/solution distinction of the functional method observes the phenomenon to be studied as a solution to a problem, the event/recursivity distinction leaves the question of communicative "success" (operations gaining connection) open and thus makes it an empirical question. If the operations gain connection we call it »autopoiesis « - and if they do not I suggest we call it »autolysis« .

\section{Autopoiesis and Autolysis}

At an operational level, the concept of autopoiesis is fundamental. A central aspect of autopoiesis is the above mentioned premise of operational recursivity, a recursivity that always draws a boundary between the system and its environment. On the one hand, the concept of autopoiesis does not, according to Luhmann, have much explanatory power (Luhmann 1997, 66; 2004, 114). But, on the other hand, it is a theoretical premise with important theoretical and epistemological consequences. Or, as Luhmann puts it, »Man gewinnt 
mit diesem Begriff einen anderen Ausgangspunkt für konkretere Analysen, für weitere Hypothesen oder für einen komplexeren Einsatz von Zusatzbegriffen." (Luhmann 2004, 114).

This article does not question the value of the concept of autopoiesis. But it does have an interest in the failure of autopoiesis and suggests autolysis as the counter-concept. This is not the same distinction as between autopoiesis (self-production) and allopoiesis (other-production). Rather it is between selfproduction and self-dissolution. Luhmann borrowed the concept of autopoiesis from biology to refer to the »self-productivity« of systems (Luhmann 1995, $32 \mathrm{ff}$.). Contrary to the concept of autopoiesis, autolysis is a well-established and non-controversial biological concept. It refers to the enzymatic digestion of cells by enzymes present within them (www.medterms.com). I use autolysis as a concept for the processes of self-dissolution in social systems. Like autopoiesis, autolysis does not have much explanatory power, but the concept is, I believe, able to direct the analyses in novel directions that are unlike those suggested by autopoiesis.

Let me begin developing the concept of autolysis with a terminological problem. Since operations are virtual and only become real when further operations connect to them, what do we call the communicative events that do not establish connections (or establish connections for a shorter period of time than expected) $?^{2}$ An operation - for instance, a decision - that does not establish connection is not really an operation. Inspired by Urs Stäheli we may call these unfulfilled operations »noise«. Stäheli puts it the following way: »Ein reines Ereignis verfügt daher über keine Bedeutung: Solange es nicht verstanden ist, bleibt es unbestimmter Lärm « (Stäheli 2000, 103). Noise is thus an utterance that does not obtain connection or understanding. ${ }^{3}$

The concept of noise proposed in this article is inspired by Stäheli (2000; 2003) but differs from his concept in a number of ways. In his attempt to think the idea of communicative failure, (»das Fehlschlagen von Sinnprozessen«), he generalizes noise to be a part of all communication, which is constantly accompanied by noise. »Noise is produced within every event of communication as an unbridgeable gap between an utterance and its understanding." (Stäheli 2003, 246, my emphasis). Noise is necessarily there because of the rupture between information/utterance on the one side and the understanding on the other. Understanding is never identical with information/utterance, there is always noise on the line. As Stäheli puts it, it is »the very operation of order(ing) which produces a noise of its own, making it impossible to ever establish the fullness of social order.« (Stäheli 2003, 244, my emphasis).

2 Luhmann $(1997,72)$ avoids this problem as he decides that, »Die Zeitpunktgebundenheit der Operation Kommunikation bezieht sich auf den Zeitpunkt des Verstehens auf Grund der Beobachtung einer Differenz von Information und Mitteilung."

3 This definition parts with more traditional information theory, where noise is understood as disturbances that hinder signals in fully reaching the receivers (Lester/Koehler 2003). 
Stäheli's way of conceptualizing noise is an attempt to develop a different kind of concept of the political within systems theory. But there is reason to think that Stäheli simply turns noise into a transcendental condition of communication, and not a contingent phenomenon whose production can be empirically analyzed. Instead, this paper defines noise as utterances that do not obtain understanding, as in Stäheli's first formulation. Noise is something which may or may not be produced within the communication, within systems. Noise presupposes a system - without a system we would not be able to recognize noise as noise, as it is only noise within a recursive network of operations. And the noise itself has an ambivalent status. Is noise produced within a system part of the system? It is neither ascribed to the environment nor the system. Noise is thus a borderline phenomenon between communication and non-communication (Stäheli 2003, 206). Contrary to the clear drawing of boundaries in the delineation of autopoiesis, the borders here are questioned by noise. On the one hand, the noise is not part of the recursive network of the system. On the other hand, noise is recognized on the inside of the system as something produced in the system. Inspired by Mary Douglas, we may say that noise is the dirt of communicative systems (Douglas 2002). The advantage of the proposed concept of noise is that it does not turn it into a condition stemming from either the environment, which is how Luhmann understands noise (Luhmann $2000,58)$, or from the rupture within communication (Stäheli).

The idea then is to define autolysis as the process through which noise is produced within social systems. In autopoiesis, operations are a result of earlier operations and call forth still further operations. In autolysis, noise presupposes earlier operations but does not call forth further operations. And contrary to the concept of autopoiesis, which does not admit gradations (Luhmann $2000,51)$, there may be different levels of autolysis in a system. It may produce more or fewer events that do not establish connection. Even though we cannot study the absence of communication, we can study how noise is created within communication, i.e., what actively lowers the probability of events becoming operations by obtaining connection. The question is, are we able to localize mechanisms within social systems that foster dissolution?

Obviously, noise is not absent from systems theory. On the contrary it is an important methodological starting point as outlined in the introduction. For Luhmann the necessity of dissolution is a truism, as it is a precondition for variation, adaptation and thus reproduction (Luhmann 1995, 48). Complex systems need a certain element of instability in order to protect themselves against stagnation and in order to be able to respond to themselves and their environments. As Luhmann puts it, »A system must not simply maintain sitself^, it must maintain its sessential variables< (Ashby). This includes the interdependence of dissolution and reproduction « (Luhmann 1995, 369). Especially in his writings on evolution (Luhmann 1997, 413ff.; 2000, 330ff.) Luhmann comes close to analyses of the production of noise. At an operational level social systems 
produce variations which are exposed to positive/negative selection (Luhmann 2000, 351ff.). Luhmann especially describes rejection of utterances and oblivion as two mechanisms creating non-connectivity (1997, 459ff.; 576ff.).

But even though Luhmann recognized an interdependency between dissolution and reproduction, his main interest was not dissolution but production. He used his sense of fragility and deconstruction as a way to strengthen his analyses of construction processes. He dealt with dissolution out of an interest in its importance for production. And the overall aim of his evolutionary theory is not to analyze decay and dissolution but to explain the emergence of increasingly more improbable (because of their ever more prerequisite conditions) structures. In general, Luhmann's systems theory has been more interested in ordering than in the active production of noise. The result may be that disorder is left as a fact, which does not call for analysis or explanation. But the preference for »order over perturbation « (Luhmann 1995, 83) is, as Luhmann puts it, only a preference. And we may have other preferences.

Now, if we relate the proposed concept of autolysis to the distinction event/recursivity, it should be clear that this distinction may be sensitive both to autopoiesis (focusing on successful recursivity) and to autolysis (focusing on failing recursivity). With recursivity as an empirical variable (there may or may not be recursivity) instead of a condition, the operational analysis may be seen as a supplement to analyses asking how the improbability of the communication is handled. In the next section we shall see an example of how different the communication in an organization appears, depending on whether we look for autopoiesis or for autolysis.

\section{A Noisy Organization}

Let me first briefly present the organization, giving the empirical material for the observation of autolysis. Both the examples of unsuccessful operations and the following analysis of the mechanisms involved are based on an in-depth analysis of a single organization, namely the Frederiksborg County Health Authority. In 2006 the County had four general hospitals (Hillerød, Helsingør, Frederikssund and Hørsholm), but the number of hospitals varied during the period studied as a result of mergers and new differentiations. There is also a psychiatric hospital, but it was left out of the analysis. The County is situated in North-Sealand, Denmark, and has a population of 371.000. The Health Authority has approx. 4600 employees. The Authority was analyzed as an example of a central aspect of the modernization of the Danish public sector: the differentiation (decentralization) of administrations into self-referential organizations. In the study I attempted to reconstruct the history of the major decisions made in the Health Authority during the period 1980 to 2002. This was not, however fully possible. As a matter of method, the observation of operations is in 
principle impossible because the selections involved are invisible (Luhmann 2000a, 206). Furthermore, it is empirically difficult to say when a decision was made. Typically, decision-proposals are made, discussed, adjusted, and proposed again until the decision is at last formally confirmed. But when exactly in this chain of communication was the decision made? And since the decision is not realized until further decisions connect to it - a connection which may not even be explicit - we have to do more than use hindsight to reconstruct the decision to be able to see which decisions it connects to; we also have to follow how subsequent decisions connect to it. The observation of failing operations is even harder. Here we are interested in something that does not happen; we want to be able to say that no other decisions connected.

These methodological problems mean that the observation cannot be a representation of the process, but must always be a reconstruction, for the most part based on traces of the processes and their observation by members of the organization. I limited the analysis to decisions about decision-premises, i.e., decisions directed towards other decisions (Luhmann 2000, 222ff.) in a specific period of time (1980-2002). These limitations made possible, to a fair degree, a survey of which decisions gained connection and which did not.

The reconstruction of the decision processes is mainly based on more than one hundred written documents (plans, proposals, minutes etc). As Luhmann puts it: texts are the memory of social systems. The reconstruction is also based on attendance of twelve meetings at different levels of the organization. Furthermore, it is based on fifteen interviews with key-personnel. An interview can be seen as an interaction between researcher and the respondent and should thus not be confused with the organization's communication. But interviews can be a way for the researcher to establish a second order observation of the organization and thus provide an impetus for forming hypotheses about important characteristics of organized communication. These hypotheses which must in turn be followed further through the analysis of documents and observations of organizational communication at meetings etc.

It is of course possible to observe the material collected against different guiding distinctions. I observed it as operations and observed these operations with the distinction event/recursivity. By studying the decisions of decision-premises (decisions made in order to limit the latitude for a plurality of decisions in the future - principally decision-programs, staff and the organization of the organization (Luhmann 2000, 225)), I firstly reconstructed central aspects of the autopoiesis of the organization. It was striking how the organization in the period studied emerged as an ever greater network of recursively connected decisions. The organization made still more decisions about more and more (see also Knudsen 2004, 2005). Moreover, it was remarkable how the decisions in the county increasingly referred to other decisions in the county and less and less to legislation, circulars and the like. Thus the Frederiksborg County Health Authority appeared as a successful realization of a general strategy aiming at 
a transformation of public sector units from administrations to autonomous and self-modernizing organizations. And in this process it developed its own autopoiesis with operational closure, recursively producing both decisions and decision premises (its structures).

But success has a downside. During the 1990s one can observe an increase in uncertainty, confusion and in decisions failing to gain connections. Still more decisions are rapidly changed or not connected to at all - thus turning out not to be decisions even though they frame themselves as such. This process was articulated in the observations of the staff I interviewed. Generally, they expressed great uncertainty regarding the current changes and they also had different interpretations of what was actually being decided. As a consultant said, »they plan the way blind people box" , and the "they" was unclear too. This made me reconstruct the decision processes once again - now focusing on the lack of recursivity. This made it obvious that a considerable amount of decisions did not obtain recursivity. Let me mention some of the more prominent examples of decisions in Frederiksborg County Health Authority that either did not, or only for a shorter time than expected, establish connection.

- The overall development of the organization is decided in the health plans, which are drawn up every four years. The health plans from 1992, 1997 and 2001, however, were changed strikingly in the middle of the period - meaning that central decisions in the plan were overruled and did not gain connection the way they were supposed to do.

- In 1993, the decision to have Hørsholm Hospital as a separate hospital was reversed as Hørsholm was merged with Helsingør Hospital. In 2000 this decision was again reversed as Hørsholm was made an independent hospital with its own board. At the same time major changes were made to the hospitals functions: acute functions were moved to other hospitals and elective functions were gathered at Hørsholm. In 2002 it was decided to sell Hørsholm Hospital. In 2003 it was decided not to sell Hørsholm Hospital. In 2004 it was decided to investigate how much it would cost to sell Hørsholm. In 2006, the fate of the hospital is still unclear.

- In 1998, it was decided to merge the three orthopaedic wards in the county from January 2000. In the following period several decisions and changes were made in line with this decision. In April of 2000, it was decided not to merge the wards after all. In the spring of 2003 the decision to reverse the decision was reversed: it was again decided to merge the orthopaedic wards.

- In 1997, it was decided to reverse the decision that hip surgery was to be carried out at three different hospitals. Hip surgery was centralized at Frederikssund hospital, which educated its staff to handle the operations. In 1999, the decision was reversed and hip-surgery was placed at Hørsholm Hospital. 
- In 1992, it was decided to move the maternity ward from Helsingør Hospital to Hørsholm Hospital. This decision was reversed in 1995 when the ward was moved from Hørsholm to Helsingør. In 2003, it was decided to move the ward to Hillerød.

- In 1999, it was decided that the orthopaedic consultants were to be placed at Hørsholm Hospital. This decision was never realized.

- In 2000, it was decided to establish a public-private company to operate the hospital laboratories. In 2001, it was decided not to establish such a publicprivate company.

To the above mentioned examples may be added numerous decision-proposals which never got beyond proposal status. And of course, the decisions mentioned caused many smaller decisions to be made in line with the decisions, which were also subsequently reversed. In the next section, I will point out mechanisms at work in the case that actively increase the probability of noise.

\section{Mechanisms creating noise}

It is a theoretical assumption of systems theory that decisions are improbable. That they do not obtain connection should not surprise us and therefore does not call for any explanation. This theoretical assumption is, I think, not always productive as it may block analyses of mechanisms that actively increase the level of noise in an organization. Noise is not just a result of malfunction or the absence of mechanisms that are supposed to increase the probability of connectivity. In relation to the concept of autopoiesis, we have concepts for mechanisms which increase the probability of connection (structure, symbolically generalized media and the like). And related to the concept of autolysis there are also mechanisms that increase the improbability of connection. In this section I will show that it is indeed possible to identify some of these mechanisms. In Frederiksborg County Health Authority, it is not least the mechanisms supposed to deparadoxify (Luhmann 1993a; 2000) the decisions (and thus increase the probability for connection) that create noise. ${ }^{4}$ In the following, I show four

4 In Luhmann's organizational theory the idea that decisions are paradoxical and must be deparadoxified in order not to paralyze the communication is central (Luhmann 1993, 2000, 123ff.). Luhmann has different ways of formulating what the paradox of the decision is. But the central point is that a decision only is a decision if it has another side (if an alternative decision could be made). Thus the decision is both the same (the indicated side of the distinction) and something different (the distinction). In this paradox lies an undecidability which makes the decision contingent. Both sides of the distinction could be indicated and the decision cannot avoid communicating this. Thus the decision also communicates its own self-critique, i.e. that it could have been made otherwise (Luhmann 2000,142). This expression of the contingency of the risks of decision threatens further connectivity: why connect to a decision which tells that it could also have been made otherwise? As organizations none the less exist, Luhmann concludes that they have found ways of making the paradox less disturbing. His organization theory is centred around this idea and the analysis of how it is done. The central term here is 
noise producing mechanisms at work in the case analyzed: excess-communication, instability, demotivation and the autokatalysis of noise.

\section{Excess communication}

When decisions do not obtain connection, the process may be described as a kind of oblivion. If remembering is to make something absent present, then oblivion can be defined as lost potentiality: the absent which could have been made present can no longer be made present. The decisions one could have connected to, one no longer connects to. Umberto Eco formulates a central oblivion mechanism, when he writes »One forgets not by cancellation but by superimposition, not by producing absence but by multiplying presences. ... Thus, it is possible to forget on account not of defect but of excess. « (Eco 1988, 259-260; see also Lachmann 2002, 379; Esposito 2002, 29f.) On this view, lack of connection, i.e. noise, would not be due to a lack of information, but rather to an abundance of it (a phenomenon also well known in stress-research where a temporary dementia can be caused by a too high level of stress). It is a question of information overload. Communicative excesses, the production of ever more decisions, increase the risk that the decisions never becomes anything but noise, or »decay « prematurely. Or in Luhmann's somewhat more functional formulation: the system relieves itself by means of oblivion (Luhmann 2000, 352). In Frederiksborg County Health Authority this is very much the case. In the 1990s it was characterized by a huge growth in decisions. More and more decisions were made about more and more issues. The organization was overloaded with decisions and became deficient to its own speed and complexity.

The question is what creates the growth in decisions. In the case of Frederiksborg County Health Authority, several mechanisms triggering growth may be identified. The mechanisms are related to strategies of deparadoxization. The most prominent are the following:

1) Luhmann describes the form of decision as being open/closed contingency in the time-dimension. Before the decision is made, the decision is contingent, neither necessary nor impossible, as otherwise it would not be a decision but a calculation. After the decision the contingency is closed, another decision is no longer possible (but the contingency remains - otherwise it would for instance not be possible to regret decisions)(Luhmann 2000, 170). I think Luhmann's description of the form of decision as open/closed contingency needs to be differentiated. If we were to make a typology of decisions, we would find that some decisions open more contingency than they

deparadoxization. And to deparadoxify means to make the contingency of the decision less visible, to displace it to a less disturbing place. This can be done in multiple ways, for instance by displacing the reason for decision to a decision maker or to decision premises. 
close. As they close some questions, they may open up others. For example, in 1995 it was decided to divide some of the functions between the hospitals in Frederiksborg County Health Authority. The hospitals did not all have to carry out the same functions. This was a decision opening a long line of questions. Which functions should be centralized, at which hospital should which functions be placed, how should they be organized, should each function have its own management, etc.? As Baecker puts it, »Die Entscheidung arbeitet mit Konstruktionen von Alternativen, die dort eine Wahl eröffnen, wo bisher nur die Wirklichkeit als solche sichtbar war.« (Baecker 2000). Thus some decisions open more contingency than they close. And often the contingency that is opened calls for more decisions.

2) In Frederiksborg County Health Authority, one may also observe decisions whose preconditions need to be established. The operations or decisions point forward, they are based on decisions yet to be made (see also Clam $2000,74)$. A shared management is, for instance, a precondition for the centralization of identical functions, because someone has to be responsible for the coordination between the geographically separated hospitals. The lack of sufficient ground must be compensated for with new decisions. Thus the lack of sufficient preconditions drives the system forward and forces it to make ever more decisions. ${ }^{5}$

3) Just like in the rest of the Danish public sector, there was a considerable growth in different kinds of self-observation (observing types of activity and consumption, doing evaluations, new and more detailed kinds of accounting etc.) in Frederiksborg County Health Authority during the 1990s. Some of the dominant types of self-observation observe the degree of connection between some major decision-premises (the budget for instance) and the (costs of the) plurality of the many single decisions. So, in order to stabilize itself the organization irritates itself with surplus information, information which it has to react to later - with more decisions.

4) One of the answers to the increasing number of decisions is the differentiation of the organizational system into subsystems. The wards get their own budgets and are supposed to find their own ways of fulfilling centrally defined goals. The result is a kind of intensifying of decisions - ever more areas are made subject to decision. The differentiation makes it possible to make decisions that are otherwise not possible. It is difficult for the organization as such to decide upon the specific targets that individual wards should aim for. But with self-referential wards the organization may decide that wards are to have targets - but they have to decide themselves which targets they want.

5 This may also be part of an answer to Viskavatoff, who calls for an explanation of why communication is produced (Viskovatoff 1999, 494): Communication is produced because communication produces a need for more communication. 
5) Self-descriptions in the form of values, plans, visions and the like may be seen as an answer to the increasing organizational complexity emerging along with differentiation. In Frederiksborg County Health Authority one may, however, observe that the different kinds of self-descriptions do not win any authority. They are quickly changed, forgotten or they are too general to function as a stable reference for more specific decisions. Thus the self-descriptions tend to increase the complexity of the organization rather than to reduce it.

These are some of the decisional dynamics in the case. The organization produces more decisions than it is able to connect to and therefore an increasing amount of virtual decisions become noise instead of real decisions.

\section{Instability}

Instability may also create noise. Luhmann defines instability in the following way: »One should speak of instability with respect to the uncertainty of the connective value of events ... the concept refers to the system's autopoietic reproduction, and it means that the codes and programs that hold in this reproduction do not determine precisely what happens." (Luhmann 1995, 368) Within certain limits, instability is a precondition for reproduction and renewal. But if the uncertainty about the »connective value of the decisions « becomes too great then the probability of connection is lowered. In this section I point out three mechanisms increasing the instability in the county.

1) The growth in the amount of decisions contributes to the instability. Which of the many decisions should one connect to? What do they imply and what would be the appropriate follow-up decision? Decision-premises increase the probability of decisions connecting to decisions by limiting the possible space of decisions (thus increasing the chance that the decisions made within this space actually gain connection). But during the 1990s the decision premises of the county became very complex and it became necessary to choose among the many, and partly contradictory, premises. A new openness was introduced - and uncertainty increased.

2) Uncertainty is also created by means of the different ways the organization deparadoxifies its decisions. Deparadoxization occurs as one displaces the paradox from the decision to the premise for the decision. But it may also be done in different ways - as can be seen in Frederiksborg County Health Authority (see Knudsen 2005 for a more detailed analysis of displacements and the effects of them). In Frederiksborg County Health Authority we may observe a series of displacements routinely used when decisions are made. Hearings displace the decision (and the inherent paradox) from identifiable decision-makers to a confusing amount of members and sub-systems. This does, of course, multiply the amount of decisions, as the hearings result in decisions about decisions 
(see also Luhmann 1981b, 344ff.). But the hearing-process typically produces several versions of the "same « decision. So, in addition to the decision that is finally made, remnants of earlier proposals may circulate, which may be used as information for further decisions. Arguments for decisions displace the paradox of the decision to the reasons for it. Dilution of decisions displaces the paradox by deferring it to the future, when it has to be decided what was actually decided earlier.

The different kinds of displacements have a tendency to create uncertainty and thus instability. They make it uncertain who made the decision, why it was made (as there are often numerous, but not always coherent, arguments for the decision) and (because of the dilution) it becomes uncertain what was actually decided. During the processes of hearings it becomes unclear when the decision was actually made. The decisions seem to emerge without anyone really knowing why or when they were made. The uncertainty produced lowers the probability that the decisions will gain connection. A typical reaction to selfmade uncertainty is to develop conspiracy-theories. And they are difficult to get rid of. Sincerity is difficult to communicate: the more one protests one's honesty the more suspicious it becomes (Luhmann 1995, 150). The many polished arguments may be seen as a strategy aimed at hiding »what is really the purpose of the decision. This mistrust may give rise to further decisions aiming at increasing the level of trust in the organization (e.g., by providing more information and having more dialogue). This is a dangerous strategy as the dialogue may lead to disappointment when all the good arguments do not seem to have any result. The conspiracy comes to look plausible after all.

3) A different kind of displacement can be found in the way the organization uses meetings and a strategy of personalization. By personalization the burden of deparadoxization is displaced to the single member of the organization. It is up to individual members to make certain decisions successful, i.e., to make them gain connection. This may be a risky strategy as it depends on the individual members and the other members' inclination to connect. When it is left to individual members to realize decisions (without being able to displace the paradox to official decision-premises) the organization has trouble maintaining its decisions - especially in times of rapid replacement of members. If the person leaves the organization, the organization also loses its decision premises. And in the Frederiksborg County Health Authority there was a rapid change of managers in the period under study. When these people disappear the uncertainty stays. This, of course, is an uncertainty that can be explained by personalization. »He was not the right man for the job, « or, »The managers are not good enough «. Personalization is thus also a means to ascribe guilt when decisions fail.

Through personalization the problems associated with getting decisions to establish connection is handled by leaving it to people who shave connections to make decisions. Meetings are used as a parallel strategy. Meetings leave it to 
interactions to make decisions. Interaction is communication structured not by decision premises but by the persons present (Seidl 2005). But where meetings, on the one hand, may be seen as a way of relieving the organization of its insufficient decision premises, they may on the other hand contribute to uncertainty and complexity. The decisions stemming from this interactional logic are not always consistent with the rest of the decisions that are made in the organization. And what has actually been decided at the different meetings? To use meetings as a tool to make decisions is risky, as it increases complexity and the risk of coming into conflict with decisions made at other meetings.

\section{Demotivation}

A further mechanism in the production of noise is related to the motivation of the members to connect to decisions. The more complex, impenetrable, timeconsuming, unstable, arbitrary, and »conspiratorial « the organization becomes, the less motivation is available. Time-consuming processes that only lead to failing or quickly changed decisions foster frustration and disappointment. What Luhmann called "gezielte Unaufmerksamkeit« (Luhmann 2000, 116, note 78) (purposive inattention) emerges, that is, »Unaufmerksamkeit« regarding decisions. Members stop engaging in new decisions, they stay away from meetings, do not respond to hearings - or they simply leave the organization completely. In the period 1998-2002 ten different people held the three positions on the board of directors. And at the level of middle-managers there was a very high level of replacement. The integration between the psychic systems of the members and the organization becomes low and the members may, as one of the managers put it, become recalcitrant.

\section{Autocatalytical noise}

The fourth mechanism that creates noise is the noise itself. Luhmann uses the term autocatalytical as a term for the way social systems create the problems which they emerged as solutions to (Luhmann 1995, 120f.). But one may also use this figure to describe the production of noise. The above mentioned noisecreating mechanisms have self-perpetuating vicious circles built into them. The excess communication produces noise, which may increase uncertainty, which the organization tries to overcome by making more decisions, which thus further swell the excess communication. And when the demotivation (created by the energy wasted on what turned out to be noise) is met with decisions aiming to increase motivation by increasing participation, then new disappointments are likely.

But the autocatalysis of noise does not only move from past »decisions « to present noise. The reverse may also be the case. Present noise may create noise in the past, when past decisions are transformed into noise. As decisions are 
realized in recursive chains, noise may also travel back in these chains. It is just like in the board game Othello, where a single white piece at the end of a line may turn all the intervening pieces over, making them change from black to white. History is never over, and whether something is noise or communication is decided by subsequent operations. The decisions made from 1998 and onwards concerning the merger of the orthopaedic wards became noise when the decision was cancelled in 2000. Until then, they had been decisions.

Noise is infectious. When members observe that not all decisions gain connections then other decisions become less binding. An undecided decision premise emerges, making it easier not to connect to decisions. At the same time there will be a need for more decisions because of the uncertainty that the organization produces about which decisions are actually decisions and which are not. The organization has to decide how to distinguish between decisions and noise.

\section{Summing up}

Above, I have focused on failing decisions in Frederiksborg County Health Authority. It is striking how many of the operations did not lead to anything, or failed to connect. As an explanation of the high level of failing decisions in the organization I pointed out four mechanisms that actively contribute to this production of noise. Together these mechanisms produce ever more decisions which fail to gain connection. Of course, there must be something solid in the first place, which can dissolve, so there can be no autolysis without autopoiesis. But an organization producing as much noise as the Frederiksborg County Health Authority $\operatorname{did}^{6}$ might as well be described as an autolytical organization, rather than an autopoietic one.

\section{The Observation of Noise}

Even though noise is defined as utterances that do not gain connection, i.e., that do not discipline further behaviour, the noise may have significance when it is observed as noise (otherwise one might say that the noise is followed by silence where everybody acts as if nothing had been said at all). If decisions that fail are observed and thus, as failures, form expectations regarding further communication, then they may have a structurating function or formative role in the system. When observed, noise may thus influence communication without itself being communication. In the Frederiksborg County Health Authority case, noise is observed differently depending on who is the observer. One may

6 Related to yet another reform of the Danish public sector the 16 counties (including Frederiksborg County) were in 2007 merged into 5 regions. 
distinguish between two generalized observations: a) the formal observations of the organization manifest in plans and different kinds of accounts b) the observation of the members of the organization.

If we start with the formal observation of noise, it is primarily a non-observation: the noise is ignored. Failed decisions are ignored and forgotten. Here the non-connectivity has the form of silence rather than the form of noise. The non-connectivity is unobserved, a non-event. This oblivion is related to a strong focus on the future. Plans and visions are the two dominating types of self-description - and both reflect the organization as a future organization. What is of interest in the past is often how the future was conceived, not how it actually materialized. For instance, budgets are made on the basis of past budgets (i.e., past expectation of the future) not on the basis of the accounts.

Not only is the organization forgetful, it is also blind when it comes to organizational activities. There are still more observations directed towards the work of the health professionals. But organizational activities like meetings, hearings, the writing of decision proposals and reports are systematically un-observed. It is un-observed which decisions gain connection, how long they last, which ones become noise and how many resources a certain decision costs. This oblivion and blindness may be a way for the organization not to be impeded by its own noise. Instead of focusing on the noise it focuses on the successes. It seems to follow the maxim of Rochefoucauld: »To succeed in the world, we do everything we can to appear successful« .

How the members of the organization observe noise depends on their position in the organization. But there is a certain general pattern. For one thing they do remember more unsuccessful decisions, for another they observe in lines of conflict. When decisions decay into noise it is often explained by someone's resistance. The reasons given for resistance may be the incompetence of other decision-makers or it may be that the decisions resisted are seen as a smokescreen covering the real purpose. Thus ascribing secret purposes is a widespread activity. »It is the mayor's fault, all he wants is a prestigious hospital at our expense, « or, »all they want is to get more control over us, « are typical models of explaining why connections to decisions are not made. There is thus a widespread illusion of a master-plan behind the many and changing decisions. Ulterior motives are preferred to no motives.

\section{Perspectives}

Now, we may return to the question raised at the outset: What have we observed using the distinction event/recursivity? The distinction made it possible to conceptualize communicative failures (the production of events without connectivity) and the mechanisms involved in the production of these failures. While the functional method applied by Luhmann uses problem formulations 
that »make it possible to represent the normal experiential contents of the lifeworld as an already-successful solution ... (Luhmann 1995, 114), the observation of operations against the distinction event/recursivity may open up the messy side of communication. Operational analysis does not observe something as already successful. If we focus on lack of recursivity, we end up with a picture of the autolytical system.

In the analyzed case the distinction event/recursivity led us observe decisions without recursivity. Thus they were not really decisions but, as I suggested we call them, noise. The distinction gave us a picture of a more disorderly, disorganized, and fragile organized communication than a more functional approach would have done. The guiding distinction made it possible to observe the noise and some of the mechanisms producing the noise - and not only the solutions to the noise.

I suggested conceptualizing the production of non-connections throughout the elements of the organization as autolysis. The concept of autolysis could probably be developed further by the investigation of different forms of non-connections. Utterances that do not obtain connections I suggested to call noise, but as we saw in the section »The Observation of Noise« not all utterances without connection are necessarily noise. If the non-connections remain completely unnoticed, if they remain non-events, then silence would perhaps be another form of non-connection.

Another possibility is to develop a typology of the degrees of autolysis. I suggested seeing the level of autolysis as a continuum where mechanisms can create more or less noise. But one could try to distinguish between on the one hand the "normal « (more or less) non-connectivity taking place in social systems and on the other hand the situation in which the noise dominates. The question could then be: How much non-connectivity can a system handle without entering into a crisis - and what form would such a crisis take? Further on this could lead to a study of the after-life of autolytical systems. Maybe autolytical organizations in crisis are sometimes transformed into semantical figures, if they cease to be autopoietic recursive networks. Maybe they live on as themes in communication within other systems - a kind of zombie-organizations. This might lead to a typology of the »normal « autolytical organization, the critical autolytical organization and the post-autolytical or zombie organization.

This typology could inform further empirical investigations working with questions like: how strategic are present day organizations concerning autolysis? Do they willingly create autolytical processes in order to remain or become flexible? What kind of counter-autolytical mechanisms have organizations developed (mechanisms which can hinder the autocatalytical mechanisms of autolysis)? Does autolysis entail internal breaking-mechanisms (like: the members stop making decisions if they observe no one connects to them). How is 
autolysis observed? Do organizations today experiment with different kinds of observation of the noise within organizations?

\section{Literature}

Andersen, Niels Åkerstrøm (2003): Discursive Analytical Strategies. Understanding Foucault, Koselleck, Laclau, Luhmann. Bristol: Policy Press.

Baecker, Dirk (1999): Organisation als System. Frankfurt a.M.: Suhrkamp.

Baecker, Dirk (2000): Organisation als Begriff. Niklas Luhmann über die Grenzen der Entscheidung. Lettre International 49, 97-101.

Clam, Jean (2000): Systems Sole Constituent, the Operation: Clarifying a Central Concept of Luhmannian Theory. Acta Sociologica 43, 1, 63-79.

Douglas, Mary (2002): Purity and Danger. London: Routledge.

Eco, Umberto (1988): An Ars Obliviovinalis? Forget It! PMLA 103, 1, 254-261.

Esposito, Elena (2002): Soziales Vergessen. Formen und Medien des Gedächtnisses der Gesellschaft. Frankfurt a.M.: Suhrkamp.

Fuchs, Peter (2003): Die Zeit der Kommunikation. Pp. 321-329 in: H. Richter/H. W. Schmitz (Hg.), Kommunikation - ein Schlüsselbegriff der Humanwissenschaften?, Münster: Nodus.

Fuchs, Peter/Niklas Luhmann (1997): Reden und Schweigen. Frankfurt a.M.: Suhrkamp.

Knudsen, Morten (2004): Beslutningens vaklen. En systemteoretisk analyse af moderniseringen af et amtskommunalt sundhedsvæsen. Dissertation, Copenhagen Business School.

Knudsen, Morten (2005): Displacing the Paradox of Decision-making - The Management of Contingency in the Modernization of a Danish County. Pp. 107-126 in: D. Seidl/K.H. Becker (eds.), Niklas Luhmann and Organization Studies. Copenhagen: Liber \& Copenhagen Business School Press.

Lachmann, Renate (2002): Erzählte Phantastik. Zu Geschichte und Semantik des Phantastischen in der Literatur. Frankfurt a. M.: Suhrkamp.

Lester, June/Koehler, Wallace C. Jr. (2003): Fundamentals of Information Studies. New York: Neal-Schuman Publishers, Inc.

Luhmann, Niklas (1981a): Wie ist Ordnung möglich? Pp. 195-285 in: N. Luhmann, Gesellschaftsstruktur und Semantik. Studien zur Wissenssoziologie der modernen Gesellschaft, Band 2. Frankfurt a.M.: Suhrkamp.

Luhmann, Niklas (1981b): Organisation und Entscheidung. Pp. 335-389 in: N. Luhmann, Soziologische Aufklärung 3: Soziales System, Gesellschaft, Organisation. Westdeutscher Verlag: Opladen.

Luhmann, Niklas (1990): Die Wissenschaft der Gesellschaft. Frankfurt a. M.: Suhrkamp.

Luhmann, Niklas (1993a): Die Paradoxie des Entscheidens. Verwaltungsarchiv 84, 3, 287-310.

Luhmann, Niklas (1993b): Das Recht der Gesellschaft. Frankfurt a. M.: Suhrkamp.

Luhmann, Niklas (1995): Social Systems. Stanford: Stanford University Press.

Luhmann, Niklas (1997): Die Gesellschaft der Gesellschaft. Frankfurt a. M.: Suhrkamp.

Luhmann, Niklas (2000): Organisation und Entscheidung. Opladen: Westdeutscher Verlag.

Luhmann, Niklas (2004): Einführung in die Systemtheorie. Heidelberg: Carl-Auer-Systeme Verlag.

Schneider, Wolfgang Ludwig (1994): Die Beobachtung von Kommunikation. Zur kommunikativen Konstruktion sozialen Handelns. Opladen: WestdeutscherVerlag.

Schneider, Wolfgang Ludwig (2004): Grundlagen der soziologischen Theorie 3. Wiesbaden: Verlag für Sozialwissenschaften.

Seidl, David (2005): Organization and Interaction. Pp. 145-170 in: D. Seidl/K.H. Becker (eds.), Niklas Luhmann and Organization Studies. Liber \& Copenhagen Business School Press. 
Stäheli, Urs (2000): Sinnzusammenbrüche. Eine dekonstruktive Lektüre von Niklas Luhmanns Systemtheorie. Velbrück Wissenschaft.

Stäheli, Urs (2003): Financial Noises: Inclusion and the Promise of Meaning. Soziale Systeme 9, 2, 244-256.

Viskovatoff, Alex (1999): Foundations of Niklas Luhmann's Theory of Social Systems. Philosophy of the Social Sciences 29, 4, 481-516.

Willke, Helmut (1987): Differenzierung und Integration in Luhmanns Theorie sozialer Systeme. Pp. 247-274 in: H. Haferkamp/M. Schmid (Hg.), Sinn, Kommunikation und soziale Differenzierung. Beiträge zu Luhmanns Theorie sozialer Systeme. Franfurt a.M.: Suhrkamp.

Assistant professor Morten Knudsen, Ph.d.

Department of Organization

Copenhagen Business School

Kilevej 14A, 2000 Frederiksberg, Denmark

mk.ioa@cbs.dk 